\title{
Mitigating Policies and Strategies for Challenges Encountering Ethiopian Urban Centers
}

\author{
Daniel Amente Kenea \\ Ph.D. Candidate in Public Management and Policy, Addis Ababa University
}

\begin{abstract}
Ethiopia is one of the less urbanized countries in the world in spite of the fact that urban population is increasing rapidly. If managed proactively, urban population growth presents a huge opportunity to shift the structure and location of economic activity from rural agriculture to the larger and more differentiated service sectors and urban industrial. Yet, if not managed proactively, rapid urban population growth may pose a demographic challenge as cities struggle to provide jobs, infrastructure and services, and housing to the residents. Inline of this reality, the paper attempted to provide mitigating policies and strategies to encounter existing challenges facing urban centers in Ethiopia.
\end{abstract}

Keywords: Policies, Strategies, Urbanization, Challenges

DOI: $10.7176 / \mathrm{IAGS} / 81-02$

Publication date:March $31^{\text {st }} 2020$

\section{Introduction}

Ethiopia is characterized by low level of urbanization even by African standard, where only $16 \%$ of populations live in urban area. Despite this, it has recorded a relatively high growth rate of urban population (5.5\% annually), double that of rural areas. However, such high growth rate is not often accompanied by development in socioeconomic services and infrastructure, and economic and employment capacity of the urban centers to support the growing population (Seifu, Habte, \& Alayu, 2011)

Moreover, urban growth and urbanization process in Ethiopia is characterized by high primate city development. The 1994 Population and Housing Census indicate that Addis Ababa has 28.4\% of the national urban population and is twelve times larger than the second largest city, Dire-Dawa (Feyere, 2005). However, recently Addis Ababa as functional primate city is declining recently mainly due to the emergence of regional capitals as competitors (Seifu, Habte, \& Alayu, 2011).

If well managed, cities and towns offer important opportunities for economic and social development. They are centers of economic growth, innovation, and employment. Cities and towns also provide large efficiency benefits, which result in unprecedented gain in productivity and competiveness. They are the centre of knowledge, innovation and specialization of production and services. High concentrations of peoples in cities generate more opportunities for interaction and communication, promotes creative thinking, creates knowledge spillovers and develops new idea and technologies (UNHABITAT, 2008). Nevertheless, as cities and towns grow, managing them becomes increasingly complex. Particularly, the speed and sheer of scale of urban transformation in developing countries like Ethiopia presents formidable challenges on surrounding environment, natural resources, health conditions, and social cohesion. In cognizance of this, the coming section of this paper tried to identify strategic and policy directions needs to be followed to mitigate challenges associated with basic services, infrastructure, employment opportunities and economic development. Besides, it suggested policy options for changing the direction of migration and investment from few cities to smaller towns.

\section{Strategic and Policy Directions to Mitigate Existing Urban Challenges}

Ethiopia has a small, yet significant, window of opportunity to exploit its demographic dividend. Its labor force doubled over the past two decades, and it continues to have a very large youth entering the labor market in the years to come. Many of these young people will be moving to cities in search of employment. Urbanization could become one of the most important catalysts to tackle economic growth and job creation in the next few years, even decades. Cities should aim to create the conditions for entrepreneurs, firms, and industries to become competitive, to which end the following policy and strategic options are put forward.

1. Identify and invest in urban centers' competitive advantage

Secondary and smaller cities are seeing the growth of naturally forming industrial clusters, while Addis Ababa's advantage seems to lie in its diverse industrial structure. As the government's Micro, Small, and Medium Enterprise Strategy notes, not all cities will be able to attract medium and large enterprises in equal measure; cities will end up specializing in particular sectors and industries. Hence, urban centres in Ethiopia will have different functions, and their capital and labor needs will differ accordingly. To this end, government shall encourage discrete growth corridors (e.g. Bahir Dar-Gonder, Mekele-Dessie, Harar-Dire Dawa, and Addis Ababa-Hawassa) by strengthening inter and intra-city cluster links and providing the necessary infrastructure. In general, cities should develop their local economic development strategies and invest in quick-wins for 
identifying and exploiting their comparative and competitive advantages.

2. Identify and invest in growing the "missing middle" of companies and jobs across urban areas

Most of existing employment takes place within small, entrepreneurial firms, many of which are also informal. At the same time, new and sustained job creation in Ethiopia comes from medium and large firms. Small entrepreneurial firms seldom sustain increases in job creation. In particular, the quality of employment and associated incomes is low, suggesting that self-employment will not be a panacea for robust economic growth. Franklin (2014) finds that young people often turn to self-employment while searching for stable jobs, frequently involving long periods of transition. Wage employment is crucial to job growth and sustainability, but Ethiopia has a sizable "missing middle" - mid-sized firms that have the ability to sustain large increases in employment. Research (in Ethiopia and elsewhere) demonstrates that waged employment is associated with a fall in urban poverty and the emergence of more formal employment, the latter also increasing with city size. Stable employment in developing countries has been associated strongly with the emergence of a middle class, which in turn leads to faster growth. In fact, most waged-employment is in the formal sector, while self-employment is mostly informal and mostly young. This suggests that firm graduation from small to medium to large sizes, and the creation of stable jobs, will be crucial for growth and for poverty reduction. These patterns differ across cities (i.e. city size affects the emergence of formal and waged-employment) and so cities and towns must identify and invest in the factors that allow existing firms to expand and create new jobs, and that encourage firms to graduate, such as better regulated taxes and access to infrastructure.

3. Target interventions according to the constraints and the needs of different typologies of firms

The government of Ethiopia has already taken several steps to target job creation across the spectrum. For instance, the Micro and Small Enterprise Development Agency focuses attention on the needs of micro and small firms. Secondary cities are becoming hubs for medium-sized firms owing to the emergence of clusters, and the Ministry of Industry is using industrial zones to attract investment across different regions by large firms (whether foreign or domestic). These initiatives should be strengthened further through:

Household/Informal Enterprises: Other countries, for instance Mozambique, local governments can have a large policy remit with regard to targeting household and/or unregistered, i.e. informal, enterprises. Indeed, developing country cities have used several innovative approaches to create an environment conducive to the growth of such enterprises (Fox et al., 2005). Although returns to urban informal sector activities are significantly lower than to formal work (often because these activities offer less security of income and tenure), these enterprises provide much needed employment and services to those at the bottom of the pyramid. In cognizance with this fact, Addis Ababa has provided targeted assistance (including the provision of market place) to informal vendors to overcome key barriers. Other Ethiopian urban centers should also benchmark this strategy. Additionally, they should target bringing down the costs of doing business and living which in turn enables even micro firms to grow further.

Small enterprises: Global evidence suggests that small and informal firms produce and sell low-quality goods and services, effectively meeting the demand for these products in developing countries. And while they tend to suffer from low levels of productivity, there is much scope for increases in operational efficiency and size if they are provided an opportunity to tap larger markets, with labor, technology and other inputs to production (Fox and Gall, 2008). Thus, local and national governments of Ethiopia should provide light-touch, supportive regulation of household-enterprises, aimed at solving their constraints without adding to regulatory burdens. This could be achieved through:

i. the provision of small-scale facilities that allow enterprises to enjoy the advantages of colocation exploiting buyer-supplier, labor market and technology linkages;

ii. support the development of small-scale businesses in sectors which have significant potential and can expand symbiotically with formal sector enterprises; and

iii. creating a linkage between formal and informal sectors particularly in terms market so that they both benefit and contribute to the development of urban centers.

Mid-size enterprises: Various studies illustrates that improvements in local business licensing and permitting systems help firms to grow more rapidly. The ability and capacity of urban governments to manage their growing administrative remit (especially in cities with newly-expanded mandates) is crucial. Nevertheless, the capacity of employees working in public sector is low which negatively affects productivity. Hence, Ethiopian urban centers should consider extending some of the enterprise support services, including access to space and facilities being provided to start-ups, to existing firms to enable them to expand operations faster.

Large enterprises: Large enterprises in Ethiopia account for the majority of sustained job creation in the manufacturing sector, and their continued success has much to do with the city-level business environment including factors such as licensing, permitting and tax systems. The implementation of these systems falls under the responsibility of urban governments (even if rates and bands are set by regional and/or national government). Availability of serviced land and infrastructure also matter greatly to large investors. The federal government has taken several policy measures to support industrialization across the country, including the creation of industrial 
zones close to major urban centers, including in and around Addis Ababa and Dire Dawa. Personally, I argue that there is a need for a better understanding of how best to maximize the potential benefits of the co-location of cities and industrial zones, owing to their linkages across strategic objectives (jobs, investment), spatial policies (access to land and infrastructure) and industry-level issues (access to labor and final markets, regulations).

4. Create a competitive environment for economic growth and job creation

Private sector dynamism in Ethiopian cities is low and variable - not enough companies survive and thrive, while there remain many city economies dominated by large publicly-owned enterprises.

In the short run, it will be important to increase the capacity of urban governments to properly design and implement incentives for firms. Not only will urban governments remain the focal points for initiating and managing initiatives aimed at targeted sector interventions, but they will also be responsible for efficient functioning of factor markets and the business environment more generally. A strategic focus on economic growth and job creation will require urban governments to better understand their potential for growth, to prioritize sectors and interventions, and to design implementation strategies targeting these objectives. Key policy options that urban governments could target include:

i. identification of skills and qualifications that are required to design and implement incentives for private sector growth;

ii. initiating a network for best practice and experience exchange;

iii. leverage educational actors and private sector to target technical training and labor supply-side issues; and

iv. urban governments ought to build up in-house capacity for recurring monitoring and analysis for tracking the impact of interventions on the constraints to limit to private sector growth,

In the medium term, urban centers must provide better access to the main determinants of private sector growth (power, transport, and finance), connecting markets and consumers. Foundational and capital-intensive investments could be tackled by urban governments, but would also require multi-stakeholder analysis (supporting the process of diagnostics, prioritization and implementation), wherein private sector, regional and national governments could be leveraged. This is particularly true of projects with cross-cutting regional returns to scale and those that require private sector collaboration across sectoral supply chains. Key policy options that urban governments, in collaboration with other stakeholders, could target include:

i. identify leading investment projects that would have a transformational impact;

ii. target and leverage large-scale grants, donor funding and private sector resources, including Public-Private Partnerships; and

In the long run, cities will need to enable smarter regulations in land markets to allow for efficient allocation of land and resources.

Some of these factors might lie outside the policy mandate of urban governments but the vast majority of them can be affected directly by city officials. For instance, the importance of tax and licensing fees for firm start-ups and growth suggests that differences in capacity to carry out functions related to private sector development could have significant effects on city competitiveness. In addition, the ability to provide land and business premises in support of clusters falls within the administrative remit of city governments, and could be used strategically in line with knowledge of comparative advantage and quick wins.

5. Investing in Infrastructure

Many of the issues related to infrastructure are linked to the institutional factors of land, finance, and governance. To the extent that the options outlined above help urban governments promote more compact urbanization aided by increased authority, capacity, and financial resources, they will help make it easier for cities to invest in infrastructure. And beyond the institutional reforms, other interventions are targeted at infrastructure. This includes:

Increase cost recovery through subsidy reform and user fees: Prices for basic services are low and do not cover operational costs. Subsidized tariffs can be justified on grounds of affordability. Affordability is a real concern and the government will be unable to eliminate subsidies, but it should ensure that they are well designed and targeted. Cost recovery can be increased by capturing a larger amount of finance through user charges and, for some sectors, through community or household contributions to capital costs (in cash or kind.)

Improve efficiency through capacity building: According to Teller and Assefa (2010), operating inefficiencies cost Ethiopia's infrastructure sectors US\$451 million a year, or 3.4 percent of GDP. The largest component relates to under maintenance of infrastructure assets, which should be addressed as a priority. Hence, it's critical to address such inefficiencies mainly through effective capacity building.

Make sure not to neglect ongoing operations and maintenance: In addition to building new infrastructures, it's equally essential to adequately maintain the existing ones. According to (CSIR and CIDB, 2007), it was recognized that the "unintended consequence of constructing more and more new infrastructure, without addressing the condition of the existing infrastructure, in the attempt to address imbalances in access to services, is a widening gap in infrastructure maintenance". Hence, the urban centers in Ethiopia need to carefully consider 
the costs of adequate operation and maintenance and to include budgets for personnel, materials, and equipment to ensure that the infrastructure created is sustained.

Improve budget execution: Low execution of capital budgets in infrastructure results in losses of millions of Birr in Ethiopian urban centers, if not Billions. This is particularly the case in roads. As a result, urban governments in Ethiopia need to consider capacity building as well as effective controlling and monitoring mechanisms as a policy options to improve the properly utilization of budget.

Integrated planning of sustainable urban infrastructures: An integrated approach is the only way to avoid decisions being prepared under wrong assumptions: the prevailing preference of an "economic" view has to be replaced by a sustainable one, which includes ecological and social considerations and mid and long-term thinking. Only if potential impacts of decisions are broadly assessed, will the development of cities and towns become sustainable. To this end, both the administrative and political decision makers have to work across sectors. Free access to public data is an essential prerequisite for integrated planning, and not just data and access, but the possibility to look for specific information and trend. In most of Ethiopian urban centres there are ample constructions taking place without approved plan. Hence, as a policy option, no development, no construction, in particular no infrastructure investment should be permitted without adherence to approved larger scale plans (Master Plans). For the approval of planning documents, there has to be a transparent process, where the roles of different institutions, stakeholders, experts and decision makers are clearly defined.

6. Create inclusive and locally rooted visions for all cities and towns

There is no one top-down solution to urban sustainability but a wealth of bottom-up approaches instead. One of the strengths of cities in both poor and wealthier countries is the initiative and inventiveness of their citizens. Seizing this opportunity requires critical rethinking, application of innovative non-market solutions and the active involvement of all those concerned.

One-way information does not fulfill the contemporary requirement for the quality standards of citizen involvement. People have to be given the possibility to become the key resource of cities and towns in Ethiopia. In particular to create a more inclusive cities and towns in Ethiopia, residents should have an opportunity to participate in budgeting, stakeholder forums, and popular votes on urban issues. Besides, to make cities and towns of Ethiopia more inclusive, both in terms of participants and issues, social and budgetary agendas have to be integral parts of it.

\section{Strategic and Policy Options to Mitigate Existing Urban Imbalance in Ethiopia}

Addis Ababa attains the largest portion of the country's urban population and is a robust economic hub offering strong pull factors of better living standards than all other cities in the country like access to basic services, infrastructure and employment opportunities for citizens across the country. This has magnetized Addis Ababa as the principal city to migrate to and has propelled it to grow even larger and faster than other smaller cities in Ethiopia. As a result, Addis Ababa is constantly overburdened by the pressure coming from an exploding population growth and the difficulty associated with meeting the consequential rising demand for basic services, infrastructure, employment opportunities and economic development.

The more proportional the population of a country is across its cities, the more favorable it is, as it signifies that economic development is not confined to one specific section or city of the country but rather evenly distributed throughout, availing all people across all cities access to basic services and infrastructure. Urban primacy however is mostly associated with congestion, pressure on the available infrastructure and pollution as the population is highly concentrated in one city where there is a better economic performance and the rest of the cities in the country exhibit an imbalanced undeveloped economy.

By looking at the nature, size, speed and need of the rural surplus labor; the uneven spatial distribution and unbalanced growth of urban centres; and considering the capacity of government policy to counter the negative effects of the pressure drivers, I suggest Green Revolution and Industrial Decentralization as policy options to keep up with the race. Green revolution means introducing agriculture technology in rural areas: high-yielding varieties of grain use of pesticides, and construction of irrigation physical structure facilities and management for harvesting two or three times per year and to avoid dependency on rain fed agriculture. Industrial decentralization is defined as the spread of manufacturing employment and enterprise management from major cities to rural towns through a phased transition.

Economic literature underlines the importance of industrialization. The problem is adopting a standard industrial policy menu to the unique conditions of Ethiopia. Considering the size and growth of the surplus labor, growth in the number of small and medium towns, and the need for incentive to competitive production, I suggest the relocation of some manufacturing industries in to medium and small towns. Industrialization is conceived here as the spread of manufacturing employment, shifting of future industrial growth from cities to secondary urban centres.

The following policy and strategic options are also important considering the existing situation of Ethiopian urban centres: 
- Redistribution of investment: Various empirical studies indicate that currently most of investment activities in Ethiopia are concentrated to few cities (Addis Ababa, Hawassa, Bahir Dar and Adama). Due to this, mostly the youth (educated and uneducated) are migrating to these urban centers. This in turn is creating more pressures on those cities to provide basic services like housing, infrastructure, and employment opportunities. Hence, it's essential to divert the direction of migration and investment to smaller urban centers. This will have at least two associated positive impact. First, it creates employment opportunities for the youth and thereby reduces pressure on those few cities. Second, it contributes towards the transformation of smaller towns in their aspiration to become larger cities. To do so, large scale industries and manufacturing needs to be established in smaller towns to create employment opportunities since the vast majority of the migrants are migrating in search of better job.

- Effective urban governance and management: Managing cities and urban growth is one of the defining challenges of the twenty-first century. If managed well, cities can act as engines of growth and provide inhabitants with better job opportunities and improved healthcare, housing, safety and social development. Further, cities can contribute to national growth through increased revenue generation and political stability. Conversely, cities that are poorly planned, managed and governed can become centres of poverty, inequality and conflict. Thus, the following policy options are essential for effective urban governance and management:

a) Build the capacity of urban management;

b) Appointment on merit basis rather than pure political consideration;

c) Design a proper mechanism to effectively utilize available resources to fairly distribute basic services, infrastructures, employment opportunities and economic development to all residents;

d) Establish a partnership among the government, private sector and civil society organizations whereby one can fill the gap of the others in the provision of basic services.

\section{Reference}

Bekure Woldesemait, 1999. For a More Urbanized Ethiopia. Migration and urbanization in Ethiopia .pp. 7-16. Proceeding of the second annual conference by Association of Ethiopian Geographers, January 29-30, 1999, Addis Ababa.

C.Teller and Assefa Hailemariam (2010). The Demographic Transition and Development in Africa: The Unique Case of Ethiopia.

CSIR and CIDB \&2007), "The State of Municipal Infrastructure in South Africa and its Operation and Maintenance; An Overview," based on CSIR/CIDB Discussion Document: Towards a Framework for the Maintenance of Municipal Infrastructure: In Support of Government Growth Objective

Fayera Abdisa(2005). Urban Expansion and Livelihood of the Peri-urban Agricultural Community: the case of Addis Ababa, MA Thesis, Addis Ababa University.

Florian Steinberg, Strategic urban planning in Latin America, SINPA Number 22 (Rotterdam: Institute for Housing and Urban Development Studies, 2002).

Fox, L. and Gall, M.S. (2008) Working out of Poverty: Job creation and the Quality of Growth in Africa.

Fox, L., Bardasi, E.and K. Van den Broeck. 2005. "Poverty in Mozambique: Unravelling Changes and Determinants." Africa Region Working Paper No. 87. World Bank, Washington, DC.

Gebre Yntiso (2008). Urban Development and Displacement in Addis Ababa: The Impact of Resettlement Projects on Low-Income Households, Eastern Africa Social Science Research Review, Volume 24, Number 2, June 2008, pp. 53-77

GHK Group of companies. City Development Strategies (CDSs) Taking Stock and Signposting the Way Forward, Discussion Report for DFID and the World Bank (2000).

Hirst, P. (2000): "Democracy and Governance in Jon Pierre", ed. Debating Governance. Authority, Steering and Democracy. Oxford: Oxford University pp. 13-35.

Hossain, Farhad (1998): Administration of Development Projects by Nordic and Local Non-governmental Organisations: A Study of Their Sustainability in Sough Asian States of Bangladesh and Nepal. A Licentiate Thesis in Administrative science submitted in University of Tampere, Department of Administrative Science.

International Labour Organization (2007), Local Economic Development for Employment Generation, Peace and Security: Approaches, Tools and Good Practices in the Philippines, Report of an ILO-SRO Manila Technical Workshop, Edited by Aurelio Parisotto.

Knox, P. L., 2005. Urbanization: An Introduction to Urban Geography.2nd.ed. Pearson Education, Inc. USA. Knox, Paul L., 2012. Urbanization: An Introduction to Urban Geography.3nd.ed. Pearson Education, Inc. USA. Mara Gittleman (2009) .Urban Expansion in Addis Ababa: Effects of the Decline of Urban Agriculture on Livelihood and Food Security. A paper presented at the United Nations $17^{\text {th }}$ Commission on Sustainable Development 
Samuel Gebreselassie (2006). Land, Land Policy and Smallholder Agriculture in Ethiopia: Options and Scenarios. Paper prepared for the Future Agricultures Consortium meeting at the Institute of Development Studies 20-22 March 2006.

UN Habitat (2008). Ethiopian Urban Profile. United Nations Human Settlements Programme Regional and Technical Cooperation Division

UN-HABITAT (2002), City Development Strategies: Lessons from UMP / UN-HABITAT. Experiences from Bamako, Mali, Cuenca, Ecuador, Colombo, Sri Lanka, Johannesburg, South Africa, Santo Andre, Brazil, Shenyang, China and Tunis, Tunisia.

Warren M.A. and L.F. Weschler (1999). Electronic governance on the Internet. In G.D. Garson (Ed.). Information Technology and Computer Application in Public Administration: Issues and Trends. Hershey, PA: Idea Group Publishing 